This was of irregular shape, flattened, and broadest in the middle, from which it tapered to each end. The extreme measurements were $1 \frac{3}{8} \mathrm{in}$. long, $1 \mathrm{in}$. wide, and $\frac{1}{2} \mathrm{in}$. thick. Where encircled by the vocal cords the extreme measurements were $\frac{7}{8}$ in. by $\frac{3}{8}$ in. The narrow tapering end was directed downwards. The lungs were only slightly crepitant and contained little or no frothy fluid. The other signs were those of asphyxia.

Pimlico-road, S.W.

\section{A CASE OF ACUTE YELLOW ATROPHY OF THE LIVER.}

By D. J. Collins, M.B., B.CH., B.A.O. R.U.I., SURGEON-LIEUTENANT, ARMY MEDICAL STAFF

A PRIVATE of the 4th Battalion Rifle Brigade, aged nineteen, was admitted to the Station Hospital, Devonport, on Feb. 25th, 1894, with syphilitic iritis. The orthodox treatment was adopted, and by March 25th all traces of the inflammation of the iris had disappeared, when a yellowish tinge was noticed in the skin and conjunctiva. He complained of severe headache, anorexia, and intolerance of light; there were no fever, no hepatic tenderness, and no enlargement of the liver. The patient had never been to India and had never previously suffered from any liver trouble. On March 27th the jaundice was more intense, there were considerable bilious romiting, severe headache, clay-coloured motions, and bile-stained urine, the temperature was normal, and there was no hepatic tenderness. The area of liver clulness appeared to be diminished, and the possibility of acute yellow atrophy suggested itself. On March 28th cerebral symptoms became marked, with restlessness, delirium, and convulsive twitchings. The vomit presented a coffee-ground appearance; the pulse was quick and full, 120 to the minute ; and the tongue was dry and brown. The liver area was markedly diminished, but pain and tenderness in the hepatic region were absent. On March 29 th the patient was comatose, with stertorous breathing and dilated pupils; the liver dulness had quite disappeared, both in front and behind, the liver area being replaced by intestines. The temperature was $100.2^{\circ} \mathrm{F}$., the pulse 136 , and the respiration 40 . The urine contained bile pigment, some blood, leucin, and tyrosin. The patient died at 11 A.M. on March 30th. A post-mortem examination was made on March 31st. The body was well nourished and the skin a deep yellow colour. The liver was much diminished in size, soft and flabby, and weighed only twenty-three ounces. The capsule was wrinkled and looked almost like a bag with fluid contents. The surface was of an orange colour, with patches of dark red and purple; the section was of a dark-yellow tint, in some parts bright red, and in others entirely yellow. The gall-bladder and bile-ducts were empty the spleen was enlarged and the heart and kidneys had undergone fatty degeneration; the endocardium was stained with bile. Treatment was symptomatic. This case is interesting in its extremely acute course, only five days elapsing between its first onset and the death of the patient; and in that the liver, which was exhibited at the Plymouth Medical Society, was extremely small in size, even for this peculiar disease, weighing, as above stated, only twentythree ounces.

\section{AN UNUSUAL AND REMOTE SEQUELA OF OVARIOTOMY.}

By Walter Falia, M.R.C.S. Eng., L.R.C.P. Lond., SURGION TO THE JERSEY GENERAI HOSPITAL.

A woman aged fifty-two was admitted into the Jersey General Hospital on April 12th, 1894, suffering from a large ovarian cyst. On April 17th I performed the operation of ovariotomy. The cyst was unilocular and quite free from adhesions. The pedicle being rather broad, it was transfixed and tied in the usual way with a stout silk ligature and the abdominal wound closed with a few silk sutures, which were removed on the eighth day, the wound having quite healed. The highest temperature recorded was $101.6^{\circ} \mathrm{F}$. on the fourth night, after which it was normal. On May 3rd the patient th got up for the first time, sixteen days after the operation; she made an uninterrupted recovery and was discharged from the hospital quite well on May 17th, a month after the operation. She continued in perfect health until the end of December last, when she said she first felt pain on micturition, but did not have any medical advice for it. In Apri] she noticed a little blood in the urine. T'hese symptoms, the patient said, continued and gradually became worse until she consulted me on June 30th last. She then had all the symptoms of stone in the bladder, but would not submit to an examination. On July 19th she again consulted me as she was in great pain, and the following day I sounded the bladder and found a calculus approximately one and a half inches long and three-quarters of an inch broad. On July 26th, with the assistance of Mr. Bentlif and Mr. Sullivan, I performed the operation of lithotrity. The calculus was phosphatic and was easily crushed. On attempting to withdraw the lithotrite I found it impossible to do so without using undue force, but after some further crush. ing and manipulation I was able with more or less difficulty to withdraw the instrument, when between the blades I was astonished to find a thick silk ligature covered with a certain amount of phosphatic deposit, which easily accounted for the difficulty I had just experienced. The bladder was afterwards washed out in the usual way and all the fragments removed. The patient had no bad symptoms and in a few days was practically well. On examining the ligature carefully I found that it was undoubtedly that which had been used for tying the pedicle of the ovarian cyst.

Remarks.-It seems difficult to understand how a ligature used in tying the pedicle of an ovarian cyst could ultimately become the nucleus of a vesical calculus in a case in which there was no injury to the bladder during the operation and no difficulties whatever connected with it, the patient continuing in perfect health for about nine months afterwards. It is also remarkable how the ligature, which must have set up a certain amount of irritation and which eventually perforated the bladder, could do so without giving rise to any symptoms until it became lodged in that viscus. St. Heliers, Jersey.

\section{d attirtor}

\section{H O S P T A L P R A C T I E BRITISH AND FOREIGN.}

Nulla autem est alia pro certo noscendi via, nisi quamplurimas et morborum et dissectionum historias, tum aliorum tum proprias collectas habere, et inter se comparare.-MorgagnI De Sed. et Caus. Morb., lib. iv. Procemium.

\section{GUY'S HOSPITAL.}

CASE OF FRACTURE OF OS CALCIS; UNION OF FRAGMENTS IN BAD POSITIONS ; RESECTION OF PORTION OF OS CALCIS ; USE OF STEEI SCREW ; RECOVERY ; REMARKS.

(Under the care of Mr. W. Arbuthnot Lane.)

THIs is one of those cases which require no comment, the reasons for the performance of the operation and the operation itself being clearly given in the account. The necessity of operation for badly united fractures has not infrequently arisen in other parts of the body, but so far as we are aware this is the first time that it has been required for fracture of the os calcis. For the notes of this case we are indebted to Mr. J. 'T. Roberts, dresser.

A young man aged twenty-one years was admitted into Guy's Hospital under the care of Mr. Lane for injury to the left foot on Nov. 18th, 1893. The patient lost his balance while cleaning a second-floor window, and in order to try to save himself he jumped, alighting on his feet on the pavement below after falling from a height of thirty-five feet. $\mathrm{He}$ was immediately conveyed to the hospital, and on admission his left foot and ankle were found to be very much swollen and discoloured. When he had been anæsthetised distinct crepitus could be felt in the os calcis by fixing the posterior part of that bone with one hand and flexing and extending the foot with the other. The line of fracture, however 
could not be felt owing to the swollen condition of the foot. As there was considerable displacement of the fragments, the foot being fixed in a position of extreme abduction, $\mathrm{Mr}$. Lane wished to cut down on the os calcis and to fix the fragments in their normal position by means of steel screws, but the patient would not hear of such a procedure. Consequently the foot was fixed in as good a position as possible in the ordinary way, and gradually the swelling subsided and pain disappeared. On Dec. 12th a Croft's splint was applied, and he was discharged on the following day, supporting himself on crutches. He was readmitted under the care of Mr. Lane on Feb. 5th, 1894, for pain in the sole in front of the tubercle of the os calcis, the pain being so great that he could not stand on the foot. There was a hard swelling under the heel which on incision was found to be a mass of fibrous tissue, beneath which a bursa had developed over a prominent piece of bone. This was treated as effectually as possible. The patient was again readmitted under the care of $\mathrm{Mr}$. Lane on account of pain and stiffness in the left ankle-joint, especially at the point where the external malleolus impacted on the displaced os calcis. He began to use his foot about three weeks after his previous discharge ; but it became very painful and stiff after doing so. Finally he was unable to use it at all and he now begred to have the foot amputated. On admission his ankle was slightly swollen and there was some thickening of the os calcis below the external malleolus. Both flexion and extension of the ankle were limited, adduction and abduction of the foot were absent, and flexion and extension of the great toe were also limited. There was considerable flattening of the arch, and the foot occupied an abnormally abducted position owing chiefly to the outward displacement of the tuberosity of the os calcis. On Aug. 24th Mr. Lane broke down all adhesions in the joint and fixed the foot in as good a position of adduction as possible. On the 29th the patient was allowed to get up after dinner, but soon after doing so his foot began to be very painful, to such a degree that he could not use it, and it remained so for some time after he returned to bed. The breaking down of the adhesions having proved ineffectual, Mr. Lane decided to refracture the os calcis and screw the pieces together in a better position, it being evident that the pain was due to the altered mechanics of the anklejoint owing to the union of the fragments of the os calcis in a bad position. An incision was made across the sole of the foot, and the os calcis was exposed. It was then divided by a chisel and mallet, and a small wedge-shaped piece of bone removed so as to allow the posterior portion of the os calcis to be displaced inwards. An incision was now made over the posterior surface of the os calcis and a long screw introduced, by means of which the two pieces of bone were brought into firm and accurate apposition - the distal piece of the os calcis having been siightly rotated in order to adduct the foot from its previous exaggerated abducted position. The wounds were then sewn up by deep fishing-gut and superficial horse-hair sutures, and sterilised dressings and splints were applied. On Sept. 4th the deep sutures were taken out, the wound having united by primary union. On the 11 th the superficial stitches were taken out, the wounds having completely healed. On the 14th a Croft's plaster-of-Paris splint was put on the patient's foot, and on the 16th he was discharged. On Jan. 15th, 1895, the patient was again seen by Mr. Lane. He had been following his ordinary vocation for the previous month, walking about or standing on ladders \&c. all day from half-past six in the morning until seven o'clock in the evening. He had felt no pain or weakness in his foot during that time. Sensation was normal all over the foot, and he could walk on tip-toe and hop about on the left leg with the greatest ease.

Remarks by Mr. ARBUTHNot LANE.-This case illustrates very well the very great advantage that a surgeon can obtain by the use of the steel screw. As far as I know I could not have retained the fragments of the os calcis in the foot in a position of adduction without the aid of this very powerful mechanism, and one has the satisfaction of knowing that by its use one has converted a patient from a condition of absolute physical incapacity into one of perfect mechanical usefulness. Of course, it would have been much wiser to have fixed the fragments in their normal relationship at the time of the accident; but, as in many other cases, I found it impossible to make the patient understand the immense advantages which operative interference offered him over any other form of treatment.

\section{SALOP INFIRMARY.}

NOTES OF A SERILS OF CASISS OF DILATATION OF THE STOMACH TRLATED BY SYPHONAGE AND OTHER MW'LHODS. ${ }^{1}$

(Under the care of Dr. EDward Cureton.)

WE bring before the readers of THE LANCET a series of cases of dilatation of the stomach which have been treated in the Salop Infirmary under the care of Dr. Cureton, the cases occurring from 1890 to 1895 inclusive. He explains that the notes refer to cases of chronic dilatation, which, as is known, is mainly due to pyloric obstruction, with or without the presence of a tumour ; these cases are for the most part those of dilatation from defective tone or muscular weakness, or chronic catarrh occurring in the anæmic, or from habitual over-distension from food and drink, especially the taking largely of starchy foods, as potatoes, which generate gases, or the excessive use of aerated waters or other beverages. The patients were nearly all from the country, where a vegetable diet usually prevails to a large extent. First, with regard to the diagnosis of dilatation of the stomach, clinical evidence of this condition is afforded by the romited matter and the time when vomiting ensues, which may be several hours after food, or again after several days have elapsed, when large quantities are usually brought up, the patient being uncomfortable and distended until vomiting occurs, when usually great relief is obtained by the emptying of the stomach ; the stomach appears, however, to be only partially emptied, a residuum of sour fermenting stuff remaining behind and keeping the organ, as it were, chronically septic. Then, with regard to the romited matters, these will usually be found to be darkish brown in colour, sour smelling, and of strongly acid reaction; a thick scum forms on the top, and a brown sediment is seen at the bottom of the vessel on standing. Most of the patients complain of acidity and of the "teeth being on edge." With regard to the physical signs, these may be well marked or again nearly all absent. The chief are a want of symmetry in the abdomen as a whole, flattening of the epigastrium, and sometimes hollowness here when distended; the "stomach note" is obtained both higher and lower down than usual, and splashing sounds can often be elicited on succussion. With regard to treatment, various drugs, as we know, have been used from time to time, but the chief object of the publication of these notes is to bring under notice the great benefit which results from the use of the stomach tube in these cases. All, or nearly all, of these cases-twelve in number-have been treated by this method. The points brought out in their treatment by drugs, diet, and syphonage are as follows: 1. As to drugs alone, they only temporarily relieve acidity and stay fermentation, but the attacks of vomiting occur again after a time. The same may be said with regard to the most careful dieting in addition to medicine; but with syphonage added to these a, better result, and in some cases quite a surprising state of things, may be expected, the vomiting ceasing with the use of the tube, the pain and burning sensation and distension subsiding, and a rapid increase of flesh and strength ensning It will probably be found that the cases which yield the best results will be those of what may be described as " simple dilatation," such as occurred in some of these cases, the patients being country folk, hard-working men for the most part, who imbibe enormous quantities of fluid during the harvests, such as cider or "small beer," who have three meals a day, eat largely of starchy foods, drink tea freely, and also consume large quantities of potatoes, all of which tend to the generation of gases, with subsequent distension of the stomach and stretching of its walls, whereupon dilatation occurs, the food remaining in the stomach and setting up decomposition. No doubt sarcinæ might have been found in most of these cases if there had been time to look for them; they were present in the only case examined for them. Another point brought out by these cases is the relief which the tube will afford where there is malignant disease of the stomach. It has seemed to Dr. Cureton that the very fact of introducing a tube into the stomach stimulated the muscular walls to contract and diminish the size of the organ, and thus has had a more or less curative influence upon the muscular coats in cases of simple atonic dilatation. With reference to the amount

1 Recorded before the Shropshire and Mid-Wales Branch of the British Medical Association. 